Vol. I No. 01Hal. $21-28$

15 - Januari 2018
ISSN (Print) : 2614 - 8064

ISSN (Online) : xxxxx

\title{
Pengaruh Model Mind Map Terhadap Hasil Belajar Siswa Pada Materi Sistem Ekskresi di Kelas XI IPA SMA Swasta Prayatna Medan
}

\author{
Dewi Sutriani Saragih, Nurhasnah Manurung
}

Alumni Program Studi Pendidikan Biologi UISU ${ }^{(1)}$

Dosen PNS DPK Kopertis Wilayah I FKIP UISU ${ }^{(2)}$

\begin{abstract}
ABSTRAK
Penelitian ini bertujuan untuk mengetahui pengaruh model Mind Map terhadap hasil belajar Biologi siswa pada sub materi Sistem Ekskresi pada organ ginjal dan paru-paru di SMA Prayatna kelas XI IPA 2 tahun pembelajaran 2015/2016. Peneletian ini dilaksanakan pada tanggal 13 April 2016 sampai 28 April 2016. Peneltian ini menggunakan metode eksperimen semu (Quasi experiment) dengan populasi penelitian adalah seluruh siswa di kelas XI IPA SMA Prayatna Tahun Pembelajaran 2015/2016 yang berjumlah 170 siswa yang kemudian dijadikan sampel sebanyak 40 siswa dari kelas XI IPA 2 dengan cara pengambilan sample acak (Random Sampling). Instrument dalam peneltian ini adalah tes hasil belajar berupa pre test dan pos test.Hasil belajar siswa yang menggunakan model Mind Map diperoleh nilai yang tuntas sesuai Kriteria Ketuntasan Minimal (KKM) 70 adalah sebanyak 33 siswa $(82,5 \%)$ dan yang tidak tuntas adalah 7 siswa $(17,5 \%)$ dengan nilai rata-rata 74,35 dan standart deviasi 10,14 . Hasil uji normalitas diperoleh $\mathrm{L}_{\text {hitung }}<\mathrm{L}_{\text {tabel }}$ yaitu $0,1120<0,1401$ dinyatakan bahwa data berdistribusi normal sedangkan hasil uji homogenitas diperoleh $\mathrm{F}_{\text {hitung }}<\mathrm{F}_{\text {tabel }}=1,2<1,7$ dinyatakan data mempunyai varians yang sama atau homogen. Hasil uji hipotesis menggunakan uji $t$ diperoleh $\mathrm{t}_{\text {hitung }}>\mathrm{t}_{\text {tabel }}$ atau 6,040 $>1,718$ dengan taraf kepercayaan 0,05 maka Ha diterima dan Ho ditolak, sehingga dinyatakan bahwa ada pengaruh yang signifikan penggunaan model Mind Map terhadap hasil belajar Biologi siswa pada sub materi Sistem Ekskresi pada organ ginjal dan paru-paru di SMA Prayatna kelas XI IPA 2 Tahun Pembelajaran 2015/2016.
\end{abstract}

\section{PENDAHULUAN \\ 1. LatarBelakang}

Belajar merupakan suatu proses untuk mencapai tujuan. Proses tersebut merupakan langkah-langkah yang akan ditempuh. Bukti bahwa seseorang telah belajar ialah terjadinya perubahan tingkah laku pada orang tersebut, misalnya dari tidak tahu menjadi tahu dan dari tidak mengerti menjadi mengerti. Guru dipandang sebagai orang yang mengetahui, karena guru adalah yang dianggap paling mengerti. Guru yang menyiapkan tugas-tugas, memberikan latihan-latihan, dan penilaian. Jadi, guru memegang peran yang paling utama di kelas. Meskipun guru memegang peran yang penting di dalam kelas, harapan guru ialah bagaimana bahan pelajaran yang disampaikan guru dapat dikuasai oleh siswa-siswanya. Upaya meningkatkan keberhasilan pembelajaran, merupakan tantangan yang selalu dihadapi oleh setiap orang yang berkecimpung dalam profesi keguruan dan kependidikan. Banyak upaya telah dilakukan, banyak pula keberhasilam telah dicapai, meskipun disadari bahwa apa yang telah dicapai belum sepenuhnya memberikan kepuasan sehingga menuntut renungan, pemikiran dan kerja keras untuk memecahkan masalah yang dihadapi. Hasil wawancara dengan guru mata pelajaran Biologi di SMA Swasta Prayatna Medan, bahwa dalam melakukan proses pembelajaran guru sering menggunakan metode ceramah yang disertai dengan tanya jawab, penugasan serta membentuk kelompok diskusi. Dari proses pembelajaran tersebut bahwa hasil belajar Biologi siswa kelas XI IPA yaitu kelas XI IPA 1, XI IPA 2, XI IPA 3 dan XI IPA 4 pada ulangan harian ke dua pada semester ganjil tahun pembelajaran 2015/2016 untuk kelas XI IPA 1 yang tuntas ada 11 siswa dan tidak tuntas ada 31 siswa, kelas XI IPA 2 yang tuntas ada 26 siswa dan tidak tuntas ada 18 siswa, kelas XI IPA 3 yang tuntas 10 siswa dan 32 siswa tidak tuntas, kelas 
XI IPA 4 yang tuntas 26 siswa dan tidak tuntas 16 siswa, dimana jumlah keseluruhan siswa yaitu 170 siswa, jumlah keseluruhan yang tuntas adalah 73 siswa (43\%) dan tidak tuntas adalah 97 siswa (57\%). Dalam penelitian ini yang akan dilihat adalah hasil belajar Biologi kelas XI IPA 2, dimana sebelum diadakan penelitian ada $26(59 \%)$ siswa yang tuntas dan $18(41 \%)$ siswa yang tidak tuntas. KKM mata pelajaran Biologi adalah 70,00. Hasil belajar tersebut dapat terjadi karena kondisi pembelajaran yang masih menunjukkan keterlibatan guru yang lebih dominan dari pada keaktifan siswa. Upaya yang dapat dilakukan agar siswa dapat memperoleh hasil belajar yang lebih baik lagi maka diperlukan model pembelajaran yang sesuai dengan materi yang akan diajarkan.Sistem Ekskresi adalah salah satu materi Biologi yang dipelajari di kelas XI SMA/MA. Sistem ekskresi mempelajari organ-organ manusia yang berperan dalam proses pengeluaran. Untuk membuat siswa aktif dalam belajar Biologi tepatnya pada materi Sistem Ekskresi, diperlukan suatu aktivitas yang dapat membangun sendiri pengetahuan Biologi siswa.Mind Map atau peta pikiran untuk mempelajari tentang konsep yang didasarkan pada cara kerja otak kita menyimpan informasi. Otak sering kali mengingat informasi dalam bentuk gambar, simbol, suara, bentuk-bentuk, dan perasaan. Peta pikiran menggunakan pengingatpengingat visual dan sensorik yang sesuai dengan cara kerja otak dan membuatnya dalam suatu pola dari ide-ide yang berkaitan dengan peta jalan yang digunakan untuk belajar mengorganisasikan dan merencanakan.Mind Map atau peta pikiran dikategorikan juga dalam teknik mengetik karena pembuatan Mind Map ini membutuhkan pemanfaatan imajinasi dari orang yang membuatnya. Penerapan konsep Mind Map juga bertujuan untuk mempermudah siswa dalam memahami konsep-konsep dalam suatu materi sehingga mudah menyelesaikan suatu masalah dalam materi pembelajaran yang dihadapi. Mind Map juga membantu siswa untuk mengkonstruksikan kembali informasi-informasi yang telah diperoleh. Mind Map merupakan cara mencatat yang kreatif dan efektif bagi siswa untuk menempatkan informasi ke dalam otak dan mengambil informasi keluar dari otak. Berdasarkan masalah-masalah di atas, peneliti khawatir dengan hasil belajar siswa maka peneliti ingin melaksanakan suatu penelitian dengan judul. Pengaruh Model Mind Map Terhadap Hasil Belajar Siswa Pada Materi Sistem Ekskresi di Kelas XI IPA SMA Swasta Prayatna Medan.

\section{PerumusanMasalah}

Berdasarkan batasan masalah di atas maka yang menjadi rumusan masalah dalam penelitian ini adalah : Apakah ada pengaruh yang signifikan penggunaan Model Pembelajaran Mind Map terhadap hasil belajar siswa pada sub materi Sistem Ekskresi manusia pada organ ginjal dan paru-paru di kelas XI IPA SMA Swasta Prayatna Medan Tahun Pembelajaran 2015/2016.

\section{Tujuan Penelitian}

Adapun yang menjadi tujuan dari penelitian ini adalah :

1. Untuk mengetahui kemampuan dasar siswa sebelum penggunaan model pembelajaran Mind Map pada sub materi Sistem Ekskresi manusia pada organ ginjal dan paru-paru di kelas XI IPA SMA Swasta Prayatna Medan Tahun Pembelajaran 2015/2016.

2. Untuk mengetahui hasil belajar siswa setelah menggunakan model pembelajaran Mind Map pada sub materi Sistem Ekskresi manusia pada organ ginjal dan paru-paru di kelas XI IPA SMA Swasta Prayatna Medan Tahun Pembelajaran 2015/2016.

3. Untuk mengetahui ada tidaknya pengaruh penggunaan model pembelajaran Mind Map terhadap hasil belajar siswa pada sub materi Sistem Ekskresi manusia pada organ 
Dewi Sutriani Saragih, Nurhasnah Manurung: Pengaruh Model Mind Map Terhadap Hasil Belajar Siswa Pada Materi Sistem Ekskresi di Kelas XII IPA SMA Swasta Prayatna Medan

ginjal dan paru-paru di kelas XI IPA SMA Swasta Prayatna Medan Tahun Pembelajaran 2015/2016.

\section{Manfaat Penelitian}

Manfaat yang diharapkan sehubungan dengan penelitian ini antara lain :

1. Secara teoritis

Penelitian ini diharapkan dapat memberikan manfaat secara teoritis, sekurangkurangnya dapat berguna sebagai sumbangan pemikiran bagi dunia pendidikan.

2. Secara praktis

\section{a. Bagi Peneliti}

Sebagai sarana untuk memperluas pengetahuan dan menambah kompetensi peneliti sebagai calon pendidik.

b. Bagi Guru

Mengetahui model pembelajaran yang bervariasi untuk memperbaiki dan meningkatkan pembelajaran Biologi dan diperolehnya model pembelajaran yang tepat untuk materi Sistem Ekskresi.

c. Bagi Siswa

Tumbuhnya motivasi siswa dalam proses pembelajaran, meningkatnya hasil belajar siswa secara kognitif dan meningkatnya keaktifan siswa dalam belajar.

d. Bagi Sekolah

Meningkatnya hasil belajar siswa dalam pembelajaran Biologi, tumbuhnya motivasi guru dalam mengembangkan proses pembelajaran yang bermutu dan tumbuhnya iklim pembelajaran siswa aktif di sekolah.

e. Bagi Peneliti berikutnya

Dapat dijadikan sebagai bahan pertimbangan atau dikembangkan lebih lanjut, serta referensi terhadap penelitian yang sejenis.

\section{METODE PENELITIAN}

Langkah-langkah yang dilakukan dalam pengumpulan data adalah sebagai berikut:

Prosedur penelitian merupakan tahapan-tahapan kegiatan yang dilakukan dalam upaya memperoleh data-data yang dibutuhkan. Tahapan-tahapan tersebut adalah:

\section{Tahap Persiapan}

Kegiatan yang dilakukan dalam tahap ini adalah :

a. Konsultasi dengan dosen pembimbing skripsi.

b. Observasi awal ke kepala sekolah SMA Swasta Prayatna Medan membawa surat observasi, apakah diperkenankan melakukan penelitian di tempat tersebut.

c. Setelah mendapatkan izin, berkonsultasi dengan guru biologi yang mengajar di kelas XI IPA tentang materi-materi Biologi yang diajarkan di semester II di kelas XI IPA.

d. Penyusunan proposal penelitian.

e. Persetujuan proposal penelitian.

f. Mengurus surat izin penelitian dari FKIP UISU.

g. Konsultasi dengan kepala sekolah SMA Swasta Prayatna Medan sebagai tempat penelitian dilaksanakan dengan membawa surat izin penelitian.

h. Menyusun materi pembelajaran dengan menerapkan model Mind Map dalam bentuk Rencana Pelaksanaan Pembelajaran (RPP).

i. Menyiapkan model pembelajaran Mind Map.

j. Menyusun kisi-kisi soal dari materi pembelajaran yang akan diujikan. 
Dewi Sutriani Saragih, Nurhasnah Manurung: Pengaruh Model Mind Map Terhadap Hasil Belajar Siswa Pada Materi Sistem Ekskresi di Kelas XII IPA SMA Swasta Prayatna Medan

k. Menyususn tes hasil belajar.

1. Memvalidkan soal tes yang akan digunakan di sekolah penelitian.

\section{Tahap Pelaksanaan}

Kegiatan yang dilakukan dalam tahap ini adalah :

a. Pembelajaran diawali dengan pemberian pre-tes.

b. Memberikan beberapa pertanyaan untuk mengetahui sejauh mana pemahaman siswa tentang sub materi sistem ekskresi manusia pada organ ginjal dan paru-paru.

c. Menjelaskan tentang sub materi sistem ekskresi manusia pada organ ginjal dan paru-paru dengan menggunakan model pembelajaran Mind Map.

d. Mengadakan post test untuk mengetahui hasil belajar akhir siswa.

3. Tahap Penyelesaian

Kegiatan yang dilakukan dalam tahap ini adalah :

a. Melakukan uji hipotesis dengan menggunakan statistik.

b. Mengolah data yang didapat dari hasil penelitian.

c. Membuat kesimpulan dari hasil penelitian.

d. Membuat laporan akhir dari hasil penelitian.

\section{Instrumen Penelitian}

Data dalampenelitiantermasuk data kuantitatifyaituberupahasilbelajarsiswapada sub materi Sistem Ekskresi manusia pada organ ginjal dan paru-paru.Untukmemperoleh data tersebutdigunakanteshasilbelajar. Tes hasil belajar ini dilaksanakan pada tanggal 21 April dan 28 April 2016 di kelas XI IPA 2 SMA Swasta Prayatna Medan. Teshasilbelajar yang digunakanadalahpilihanganda (Multiple Choice) yang mempunyai 5 pilihanyaitu a, b, c, d, dan e, untuk pre-test maupun post-test. Pre-test merupakan pemberian test diawal pembelajaran untuk mengetahui kemampuan dasar siswa sedangkan post-test merupakan pemberian tes diakhir untuk mengetahui hasil belajar siswa setelah melakukan proses pembelajaran. Jumlah pre-test sebanyak 20 soal , untuk soal pre-test 12 soal diambil dari soal yang sudah valid dan 8 soal diambil dari soal UN (ujian nasional) serta dari buku Biologi Yudhistira dan Erlangga. Post-test sebanyak 30 soal, untuk soal post-test diambil dari soal yang sudah valid. Jumlah soal yang valid sebanyak 42 soal, sehingga untuk 8 soal pre-test diambil dari soal UN (ujian nasional) dan buku Biologi Yudhistira dan Erlangga. Tujuan pemberian pre-test dan post test dimaksudkan untuk mengetahui ada atau tidak adanya perbedaan sebelum dan sesudah menggunakan model Mind Map. Soal yang diberikan dapat menggambarkan valid berdasarkan isi (Content Validity) dan valid berdasarkan tingkat kesukaran (Construct Validity) maka dapat dilihat melalui kisi-kisi dibawah ini.

Langkah-langkah Instrumen Penelitian :

1. Melakukan tes awal yaitu pre-test, dimana jumlah soal pre-test sebanyak 20 soal yang sudah valid.

2. Setelah pre-test selesai, maka dilanjutkan dengan proses pembelajaran yaitu pertemuan pertama mengenai sub materi Sistem Ekskresi pada organ ginjal.

3. Pertemuan selanjutnya akan dilakukan minggu berikutnya yaitu mengenai sub materi Sistem Ekskresi pada organ paru-paru.

Setelah proses pembelajaran selesai, maka dianjutkan dengan post-test untuk mengetahui hasil belajar siswa setelah menggunakan model pembelajaran Mind Map. Jumlah soal posttest adalah sebanyak 30 soal yang sudah valid.

\section{Teknik Analisis Data}


Dalam penelitian yang dilakukan ini data hasil test dapat dikumpulkan setelah selesai test diberikan kepada siswa kemudian dilakukan penskoran.

Langkah-langkah dalam pengolahan data adalah :

Menentukan rata-rata skor masing-masing kelompok dengan menggunakan rumus sebagai berikut : (Sudjana, $2005: 67$ )

1. Menentukan rata-rata skor masing-masing kelompok dengan menggunakan rumus sebagai berikut :

$\overline{\mathrm{x}}=\frac{\Sigma f i x i}{\Sigma f i}$ (Sudjana: $2005: 67$ )

Keterangan:

$\mathrm{X}$ : Rata-rata

xi : Jumlah skor

fi : Frekuensi

2. Menghitung Standar Deviasi

$\mathrm{S}=\frac{\sqrt{n \Sigma f_{i} x_{i}{ }^{2}-\left(\Sigma f_{i} x_{i}\right)^{2}}}{n(n-1)} \ldots \ldots \ldots \ldots . . .($ Sudjana, $2005: 95)$

Keterangan:

S : Standarat Deviasi

$\mathrm{n}$ : Jumlah Responden

xi : Tanda Kelas

fi : Frekuensi yang sesuai dengan tanda Kelas XI

\section{Uji Persyaratan Analisis Data}

\section{Uji Normalitas}

Uji ini bertujuan melihat sampel berdistribusi normal atau tidak. Pengujian normalitas data menggunakan rumus uji lilieforce dengan langkah-langkah sebagai berikut

a. Data $X_{1}, X_{2} \ldots \ldots X_{n}$ dijadikan bilangan baku, $Z_{1}, Z_{2} \ldots \ldots Z_{n}$ dengan rumus:

$$
\mathrm{Z}_{1}=\frac{\mathrm{X}_{1}-\bar{x}}{S}
$$

$\bar{X}$ dan s masing- masing merupakan rata- rata dan simpangan baku sampel

b. Untuk tiap bilangan baku ini dan menggunakan daftar distribusi normal baku, kemudian dihitung peluang $\mathrm{F}\left(\mathrm{Z}_{\mathrm{i}}\right)=\mathrm{P}\left(\mathrm{Z} \leq \mathrm{Z}_{\mathrm{i}}\right)$.

c. Selanjutnya dihitung proporsi $Z_{1}, Z_{2, . \ldots .,} Z_{n}$ yang lebih kecil atau sama dengan $Z_{i}$, jika proporsi ini dinyatakan oleh $\mathrm{S}\left(\mathrm{Z}_{\mathrm{i}}\right)$, maka :

$$
\mathrm{S}\left(\mathrm{Z}_{\mathrm{i}}\right)=\frac{\text { banyaknya } \mathrm{Z} 1, \mathrm{Z} 2, \ldots \ldots \ldots . . \mathrm{Zn} \text { yang } \leq \mathrm{z}_{1}}{N}
$$

d. Hitung selisih $\mathrm{F}\left(\mathrm{Z}_{\mathrm{i}}\right)-\mathrm{S}\left(\mathrm{Z}_{\mathrm{i}}\right)$ kemudian tentukan harga mutlaknya.

e. Ambillah harga yang paling besar diantara harga-harga mutlak selisih tersebut, disebut dengan $\mathrm{L}_{\text {hitung }}$ lalu bandingkan $\mathrm{L}_{\text {hitung }}$ dengan harga mutlak $\mathrm{L}_{\text {tabel }}(\alpha=0,05)$

f. Jika $\mathrm{L}_{\text {hitung }}<\mathrm{L}_{\text {tabel }}$ maka data berdistribusi normal, sedangkan $\mathrm{L}_{\text {hitung }}>\mathrm{L}_{\text {tabel }}$ maka data berdistribusi tidak normal.

Perhitungan uji normalitas dapatdilihat pada lampiran 27 halaman116.

\section{Homogenitas}

Uji homogenitas ini dilakukan untuk mengetahui data pada data yang homogen atau tidak. Untuk menguji homogenitas ini digunakan rumus varians (sudjana, 2002: 250). 
$\mathrm{F}_{\text {hitung }}=\frac{\text { Varians terbesar }}{\text { Varians terkecil }}$

atau $\mathrm{F}: \frac{S_{1}^{2}}{S_{2}^{2}}$

$\mathrm{S}_{1}^{2}=$ Varians dari kelompok yang lebih besar

$\mathrm{S}_{2}^{2}=$ Varians dari kelompok yang lebih kecil

kriteria pengujian:

jika $\mathrm{F}_{\text {hitung }}<\mathrm{F}_{\text {tabel }}$ maka kedua sampel mempunyai varians yang sama

jika $F_{\text {hitung }}>F_{\text {tabel }}$ maka kedua sampel tidak mempunyai varians yang sama

$\mathrm{F}$ hitung dikonsultasikan dengan tabel distribusi frekuensi $\mathrm{F}_{(\alpha=0,05)}$. Jika $\mathrm{F}_{\text {hitung }}<$ $\mathrm{F}_{\text {tabel }}$ maka kedua kelompok sampel berasal dari populasi homogen begitu pula sebaliknya. Perhitungan uji homogenitasdapatdilihat pada lampiran 29 halaman 119.

\section{Uji Hipotesis}

Menguji hipotesis penelitian diterima atau ditolak dilakukan dengan pengujian statistik dengan rumus:

$$
\begin{aligned}
& t=\frac{M d}{\sqrt{\frac{\Sigma X^{2} d}{N(N-1)}}} \ldots \ldots \ldots \ldots \ldots \text { (Arikunto, 2006:306) } \\
& \text { Dengan } \mathrm{Md}=\frac{\sum d}{N} \text { dan } \sum x^{2} d=\sum d^{2}-\frac{\left(\sum d\right)^{2}}{N}
\end{aligned}
$$

Keterangan:

Md : Mean dari perbedaan pre test dengan post test

$\sum x^{2} d$ : Jumlah Kuadrat Deviasi

$\mathrm{N} \quad$ : Subjek sampel

\section{KESIMPULAN DAN SARAN}

\section{Kesimpulan}

Dari hasil penelitian diatas maka diperoleh kesimpulan sebagai berikut :

1. Nilai rata-rata pre-test sebelum menggunakan model Mind Map adalah 49,35 dan standart deviasi 11,28. Maka dinyatakan siswa tidak tuntas sebanyak 95\% pada sub materi Sistem Ekskresi di kelas XI IPA SMA Swasta Prayatna Medan Tahun Pembelajaran 2015/2016.

2. Nilai rata-rata post-test hasil belajar siswa yang diajarkan menggunakan model Mind Map adalah 74,35 dan standart deviasi 10,14. Sebanyak 33 siswa (82,5\%) tuntas dan 7 siswa $(17,5 \%)$ tidak tuntas pada sub materi Sistem Ekskresi di kelas XI IPA SMA Swasta Prayatna Medan Tahun Pembelajaran 2015/2016.

Bila dilihat dari nilai pre-test dan post test baik nilai rata-rata maupun standart deviasi mengalami peningkatan hasil belajar setelah menggunakan model pembelajaran Mind Map.

3. Hasil hipotesis dalam penelitian ini yaitu Ha diterima dan Ho ditolak dengan nilai diperoleh $t_{\text {hitung }}>t_{\text {tabel }}$ atau 6,040>1,718. Maka dari hasil analisa terhadap rumusan hipotesis menunjukkan bahwa ada pengaruh yang signifikan penggunaan model Mind Map terhadap hasil belajar siswapada sub materi Sistem Ekskresi di kelas XI IPA SMA Swasta Prayatna Medan Tahun Pembelajaran 2015/2016.

\section{Saran}

1. Bagi guru, model pembelajaran Mind Map merupakan model yang baik untuk digunakan karena mampu meningkatkan hasil belajar siswa dan untuk pencapaian 
Dewi Sutriani Saragih, Nurhasnah Manurung: Pengaruh Model Mind Map Terhadap Hasil Belajar Siswa Pada Materi Sistem Ekskresi di Kelas XII IPA SMA Swasta Prayatna Medan

yang maksimal lebih baik pembelajaran dilakukan dalam waktu yang lebih panjang atau tidak relatif singkat.

2. Bagi siswa, hendaknya dalam proses pembelajaran lebih serius khususnya ketika menggunakan model pembelajaran Mind Map agar lebih tercapainya hasil belajar yang optimal.

3. Bagi peneliti, hasil penelitian ini dapat dijadikan sumber dalam mengajar dan mampu menambah informasi, wawasan serta pengalaman dalam menentukan model pembelajaran yang tepat untuk meningkatkan hasil belajar siswa dan dapat dijadikan rujukan dan referensi apabila hendak melakukan penelitian.

\section{DAFTAR PUSTAKA}

Arikunto, S. 2006. Prosedur Penelitian Suatu Pendekatan Praktik. Jakarta:Rineka Cipta.

Arikunto, S. 2013. Dasar-dasar Evaluasi Pendidikan. Jakarta: Bumi Aksara.

Bakry, O. 1983. Tafsir Rahmat. Jakarta.

Buzan, T. 2006. Buku Pintar Mind Map. Jakarta: PT Gramedia Pustaka Utama (http://googleweblight.com/?lite_url=http://www.eurekapendidikan.com/201 diakses pada tanggal 28 Maret 2016)

Buzan, T. 2008. Buku Pintar Mind Map. Jakarta: PT Gramedia Pustaka Utama, cet.VI(http:googleweblight.com/?lite_url=http://duaenamkosong.blogspot.com/20 14/06 diakses pada tanggal 28 Maret 2016)

Buzan, T. 2010. Buku Pintar Mind Map untuk Anak: Agar Anak Mudah Hafal dan Berkonsentrasi. Jakarta: PT Gramedia Pustaka Utama. (http://kdcibiru.upi.edu/jurnal/index.php/antologipgsd/article/download/328/248 diakses pada tanggal 28 Maret 2016)

Dimyati dan Mudjiono. 2009.Belajar dan Pembelajaran. Jakarta: Rineka Cipta.

Djamarah dan Zain. 2010. Strategi Belajar Mengajar. Jakarta: Rineka Cipta.

http://id.wikipedia.org/wiki/Sistem-Ekskresi-Manusia(Diakses 20 Januari 2016)

http://library.walisongo.ac.id/digilib/files/disk1/33/jtptiain-gdls12006muahadahmi 1626-bab3 310-7.pdf (Diakses 24 Februari 2016)

Istarani. 2014. 58 Model Pembelajaran Inovatif.Medan: Media Persada.

Pratiwi, D.A, dkk. 2006. Biologi untuk SMA Kelas XI. Jakarta: Erlangga.

Priadi, A. 2010. Biologi 2 SMA Kelas XI. Jakarta: Yudhistira

Purwanto. 2011. Evaluasi Hasil Belajar. Yogyakarta: Pustaka Belajar.

Sagala, S. 2008. Konsep dan Makna Pembelajaran. Bandung: Alfabeta. 
Dewi Sutriani Saragih, Nurhasnah Manurung: Pengaruh Model Mind Map Terhadap Hasil Belajar Siswa Pada Materi Sistem Ekskresi di Kelas XII IPA SMA Swasta Prayatna Medan

Setyosari, P. 2013. Metode Penelitian Pendidikan \& Pengembangan. Jakarta: Kencana.

Shoimin, A. 2014. 68 Model Pembelajaran Inovatif dalam Kurikulum 2013. Yogyakarta: Arr-Ruzz Media.

Sudjana. 2002. Metoda Statistika. Bandung: Tarsito.

Sumiati dan Asra. 2013. Metode Pembelajaran. Bandung: Wacana Prima.

Suprijono, A. 2010. Cooperative Learning Teori dan Aplikasi Paikem. Yogyakarta:Pustaka Belajar.

Suyanto dan Asep. 2013. Menjadi Guru Profesional Strategi Meningkatkan Kualifikasi dan Kualitas Guru di Era Global. Jakarta: Erlangga

Tim Dosen FKIP UISU. 2015. Panduan Penulisan Skripsi. Medan 